\title{
Diseases Registered Among Integrated Textile Factory Workers in Ethiopia: A Retrospective Cross- Sectional Study
}

Yifokire Tefera ( $\nabla$ yifoomitu@yahoo.com )

Addis Ababa University School of Public Health https://orcid.org/0000-0001-5445-2289

\section{Abera Kumie}

Addis Ababa University School of Public Health

\section{Wakgari Deressa}

Addis Ababa University School of Public Health

\section{Magne Bråtveit}

University of Bergen department of global public healh and primary care

\section{Bente E. Moen}

University of Bergen center for international health department of global public health and primary care

\section{Research article}

Keywords: Integrated textile, respiratory disease, MSD, injury, clinical diagnosis, work-related diseases, Ethiopia

Posted Date: September 15th, 2020

DOl: https://doi.org/10.21203/rs.3.rs-66741/v1

License: (c) (i) This work is licensed under a Creative Commons Attribution 4.0 International License. Read Full License

Version of Record: A version of this preprint was published at BMC Public Health on August 9th, 2021. See the published version at https://doi.org/10.1186/s12889-021-11556-4. 


\section{Abstract}

Background: Textile and garment factories are growing in low and middle-income countries; integrated textile and garment production factories are developing, where workers are exposed to dust and dangerous, noisy machines in the work environment. Hence, workers' health might be affected negatively due to exposure to different occupational hazards. However, the health condition of workers in this sector is not adequately investigated. The aim of this study is to describe the registered diagnoses of health problems and their association to work-related and personal factors among workers in integrated textile factories in Ethiopia.

Methods: A one year recording of worker's clinical diagnoses (between March 2016 and February 2017) was gathered from the respective factory clinics in three integrated textile factories. Sociodemographic characteristics and work-related information is obtained from the factory's human resource departments. The association between the registered diagnoses and work-related factors (work in textile production, garment production and support department) and personal factors (age, gender and educational status) were studied using logistic regression analyses.

Results: The socio-demographic and clinical diagnosis statuses of 7992 workers are analyzed. The average of workers' age and years of service is 40 years and 11 years, respectively. Majority $4778(60 \%)$ of workers are females; a total of $5276(66 \%)$ of workers had 27320 clinical diagnoses; in total this causes 16993 working days lost due to sick leave. Respiratory diseases (34\%) and musculoskeletal disorders (29\%) were the most prevalent diagnoses, while injuries cause most of the days of work absence. Work department, gender and educational status are the variables that are significantly associated with several disease groups.

Conclusions: About two-thirds of the integrated textile factory workers were diagnosed with different types of diseases. The textile and garment production department workers were more affected than the support department workers, indicating that some of the diseases are related to work in these departments. Further study should investigate the occurrence of rare chronic diseases such as cancer, heart diseases, renal diseases and diabetics in relation with workers exposure profile.

\section{Background}

The textile and garment sector is growing in low and middle-income countries (LMICs); currently, the sector is expanding in Sub-Saharan African countries as a means towards industrialization (1). In Ethiopia, the integrated textile factories quoted as "Farm to Fashion" production (2), which comprise of both textile production and garment processing, have higher priority in the textile and clothing value chain than the separated textile or garment stand-alone factories. This is due to their comparative advantages of creating large employment opportunities, where some factories recruit up to or more than 6000 workers per factory. Furthermore, the departments are arranged in a chain to produce clothes from raw cotton; the fabrics produced at the weaving/knitting department use the yarn produced from the spinning 
department that process raw cotton; then, the final clothes made at the garment department use the fabrics produced from the finishing department (3). These integrated processes may constitute additional health risks for workers than those in the separate garment factories.

Traditionally, the textile industry is known to cause respiratory diseases. Since early 1900 , the main research regarding work and health in the textile and garment industry has been focused on the respiratory disease, byssinosis (4). Several studies have indicated that processing raw cotton to clothing generates inhalable dust and endotoxin that might cause respiratory problem (5-7). However, the work processes in textile and garment production expose workers not only to dust but also to other different hazards $(8,9)$. For instance, the presence of heavy machines and mechanical contact, manual handling, repetitive work and work in awkward postures as well as increased work pressure can put workers at risk for work-related diseases, such as musculoskeletal disorders (MSDs) and traumatic injuries (10-12). In the past years, studies have described various health problems among workers in the textile and garment sector (13-16). However, several of the studies are reviews and few of them are original researches that study health problems often assessed by self-report.

As mentioned earlier, work in the integrated textile factories may associated with additional health risks compared to those seen in the old factories that are only with production of fabrics $(13,17)$. The textile department workers have a direct contact with the raw cotton and dangerous machines to produce yarn and fabrics which might imply an increased risk for respiratory diseases, injuries and hearing impairment $(9,18-20)$. Workers in the garment department process the fabrics; change the sizes, colors and textures being in various working conditions and using different machines. For example, risk of MSDs due to repetitive work and unhealthy work postures $(10,12)$ and risk of cancer due to the use of different dyes (21). The establishment of integrated textile factories is rising in Ethiopia the past years; however, there is no national statistics about occupational diseases and injuries to show the health of the workers employed in the country.

In addition, despite the well-known presence of health hazards in the textile industry, in Ethiopia, Occupational Health Services (OHS) for workers is lacking. According to ILO (22), only $5-10 \%$ of the workers in developing countries have access to OHS. Nevertheless, several of the integrated textile factories in Ethiopia have health clinics; hence, it is likely that these clinics diagnose work-related diseases, but we have very little knowledge about their activities. Some of the factories have health clinics with registration books where information about workers' health can be found. Therefore, study of occupational disease in the integrated textile factory can contribute to establish a new overall picture about health risks and associated impacts in this industry.

Therefore, the purpose of this study is to describe diseases registered at factory clinics during a period of one year among workers in integrated textile factories. In addition, we examine and identify personal and work-related factors associated with the diseases. Authors hypothesize that many workers would visit the health clinics because of work-related health problems and that the factory clinics can be a source of information and knowledge about work-related diseases and injuries in the integrated textile factories of 
Low and Middle Income Countries (LMICs). Using the ILO lists of occupational diseases (23); respiratory diseases, MSD, injuries and ear diseases/reduced hearing were the main focus of discussion in this paper.

\section{Methods}

\section{Study Design}

This is a one-year retrospective cross-sectional study design, that collect workers' health data from clinics in three integrated textile factories. In Ethiopia, integrated textile and garment factories have been developed as a new way of organizing the production by including the whole production line from raw cotton to garment. The detailed production process in the integrated textile factories is described somewhere in a previous study (19).

\section{Study Settings}

Three integrated textile factories were selected for this study which fulfilled the inclusion criteria. A total of 130 enterprises are registered in the Ethiopian textile value chain; 20 of these are grouped under the integrated textile factories (24). The selection criteria for the integrated textile factories to this study include the presence of a functional integrated four main production departments (spinning, weaving/knitting, finishing and garment), working in three shifts, the presence of health clinics for both emergency and non-emergency consultations and the availability of workers' health recording system. Ethiopia had only three integrated textile factories that fulfilled the above inclusion criteria. Factory 1 and 2 are located in Amhara Regional State, $550 \mathrm{~km}$ to the Northwest and $400 \mathrm{~km}$ to the Northeast of Addis Ababa, respectively; factory 3 is located in Tigray Regional State $1300 \mathrm{~km}$ to North of Addis Ababa. These three factories 1, 2 and 3 were established in 1961, 1986 and 1992, respectively (Fig. 1).

\section{Study Population}

The study population comprises all workers in the three integrated textile factories; these are workers in factory 1,2 and 3 with the number of 1545, 1380, and 5067, respectively (Fig. 2). Workers are grouped into three broad categories: textile production department, garment production department and support department. The textile department includes workers in spinning, weaving $/ \mathrm{knitting}$ and finishing the garment department include workers in the garment production and the support department included workers from administrative and maintenance services. The main work activities in the textile, garment and support are yarn/fabric making, cloth production and technical/administrative roles, respectively. This implies that workers in various department may have different exposure risks; to illustrate this, workers in textile department may expose workers to dust, noise and dangerous machines, those in the garment department workers are expose mainly to ergonomic hazards and chemicals and support department workers may expose to mechanical and office related hazards. Furthermore, support 
department workers are occasionally enter to the production department for machine or production related support issue that may expose them to hazards in the production sections; otherwise, they work regularly in the office or in the workshops.

All three factories have similar types of services in their clinics with an outpatient department, emergency admission, laboratory facility, and drug dispensary. Each clinic are staffed with a general physician, 2-3 health officers, 5-7 nurses, 2-4 health assistants, 2-3 laboratory technicians, and 1-3 pharmacists. The clinics are primary healthcare centers; hence, they have referral system to hospitals and specialized clinics for advanced diagnosis and treatment. Since the factories function in three shifts, the clinics are open 24 hours for consultations, but only the emergency service is available for night shift workers. Overall, non-emergency cases can visit clinic outside work hours; however, workers can visit clinic for emergency health conditions while at work, but they require approval from a supervisor.

\section{Data Collection}

The data were collected from both departments of human resources and clinics of the factories. Workers' personal profile is retrieved from the registration of the human resource department in a Microsoft Excel database that contain workers' list with unique identification number, date of birth, sex, education, working department and length of years at work.

On the other hand, information about the health of the workers was obtained from the factory clinics. Each worker has a card labeled with their name and a unique identification number, which is the same to the one used in the human resource data base. The registration on the patient card includes information about date of consultation, type of diagnoses and sick leave days granted for each worker. All clinical consultations of workers from 1st of March 2016 to 28th February 2017 were extracted from the health archives of the factory clinics and registered manually in a logbook prepared for this research purpose. Clinic consultation for antenatal services, chronic disease follow-ups and visits to change the treatment regime are excluded from the study. From totally 31512 clinic consultations, 4192 were excluded with incomplete information (Fig. 2). A worker may visit the clinic for consultations more than once for the same diagnosis category or for a different diagnosis. Four nurses based in each clinic (totally 12 nurses) participated in the data collection with two days training for this work by the principal investigator. The data extraction is checked for consistency and completeness by the first author and two clerks entered the clinical diagnosis data from the logbook into the Microsoft Excel spreadsheet. Then the first author, with the support of a software manager, merge the data from the clinic and human resource on Excel sheet and transfer it to SPSS software version 22 (SPSS, Chicago, IL, USA) for analysis.

\section{Statistical Analysis}

In this study, no specific diagnostic code system is used. The clinic physicians used a large number of diagnoses types; hence, the diagnoses are grouped into the following comprehensive categories: respiratory diseases, injuries, musculoskeletal disorders, allergy, ear diseases, eye diseases, 
gastrointestinal infections, mouth diseases, peptic ulcer diseases, reproductive health problems, skin diseases, neurologic and psychiatric diseases, and other health conditions. These categories have various groups of health conditions and described as follows. The respiratory diseases include bronchitis, asthma, pneumonia, pulmonary tuberculosis, and upper respiratory tract infections. Injuries include fractures, cuts, dislocations, burns, swellings, soft tissue injuries, accident caused traumas and lacerations. Musculoskeletal disorders include back pain, neck stiffness, disc prolapse, joint pain, leg pain, myalgia and arthritis. Allergies include allergic rhinitis, allergic conjunctivitis, allergic sinusitis, allergic reaction, skin allergy and food allergy. Ear diseases include otitis media, ear infection, vertigo, ear pain and hearing problems. Eye diseases include conjunctivitis, trachoma, chalazion, presbyopia, pterygium, blepharitis, blurred vision, short sight, glaucoma. Gastrointestinal infections include intestinal parasites and dysentery. Mouth diseases include dental problem, dental carries, tonsillitis, oral candidiasis, tooth bleeding, glossitis and gum infection. Peptic ulcer diseases include gastritis, epigastric burn, hernia, dyspepsia and gastrointestinal disorder. Reproductive health problems include mastitis, pelvic inflammatory disease, dysfunctional uterine bleeding, abortion, genital ulcer, cyst, breast tumor, fistula, scrotal swelling, dysmenorrhea, cervical cancer, sexually transmitted infection and vaginal bleeding. Skin diseases include dermatitis, herpes zoster, herpes simplex, wart, skin rush, scabies, cellulitis, tinea corporis, boils, melasma, contact dermatitis and tinea capitis. Neurologic and psychiatric diseases include migraine, neuralgia, nerve problem, peripheral neuropathy, sciatica, anxiety, depression, mental disturbance, and psychosis. Other diseases include cancer, cardiac, kidney, goiter, chronic liver disease, chronic osteomyelitis, rectal prolapse, appendicitis, tumor, bone problem and insomnia.

In the statistical analysis, the diagnostic categories are the outcome/dependent variables while workrelated and personal factors are the independent variables. As mentioned earlier, the variable work department is one of the work-related factors categorized into three groups; textile, garment and support. The textile and garment department workers are directly engaged in the production and are considered to be more exposed to work environment hazards than the support department; hence the support department was the reference group for the two departments during analysis. Similarly, the personal factor, education is grouped into three categories: able to read and write, completed grade 1-10th, and those at the level of college and above. Further, age was treated as a continuous variable, while male gender is considered as the reference.

Descriptive statistics was performed to describe the different types of diseases observed and the personal and work-related factors. A logistic regression analyses were done to compute crude and adjusted odds ratios (AORs) at $95 \%$ Cls to identify factors associated with the diagnostic groups. The analysis was started by performing bivariate logistic regression for each disease group (outcome) with each independent variable. A disease diagnosis at least one time for the individual worker was counted. The independent variables associated with the disease group at a significance level of $P<0.2$ were included in the multivariate logistic regression model. In the current study, worker's age and service years were significantly correlated $(r=0.8, p<0.001)$; hence, we decided not to add the service years in the logistic regression analyses. 


\section{Results}

\section{Demographic and work characteristics}

A total of 7,992 workers are included in the observation. The average age and service year are 40 years and 11 years, respectively. The proportion of workers in the textile, garment and support departments are $40 \%, 44 \%$ and $16 \%$, respectively. The majorities (60\%) are females; the proportions of female workers are $87 \%, 40 \%$ and $33 \%$ among the garment, textile and support department, respectively. More than half (52\%) of workers had completed education level grade 1-10 while seven percent of the workers had no formal education but were able to read and write. The highest proportion of workers who had never attended formal education but able to read and write found among the support department (13\%) and lowest among the garment department (5\%). About (66\%) of the workers had been diagnosed with at least one disease in the year of observation (Table 1).

Table 1

Demographic and work characteristics in integrated textile factories 20162017

\begin{tabular}{|llll|}
\hline Variables & Category & Arithmetic mean & $\begin{array}{l}\text { Standard } \\
\text { deviation }\end{array}$ \\
\hline Age, Years & & 40 & 10 \\
\hline Service, Years & & 11 & 10 \\
\hline Gender & Male & 3214 & $\%$ \\
\cline { 2 - 4 } Education & Female & 4778 & 40 \\
\cline { 2 - 4 } & Read and write & 555 & 60 \\
\cline { 2 - 4 } Working department & Grade 1-10 & 4188 & 7 \\
\cline { 2 - 4 } & College and above & 3249 & 52 \\
\cline { 2 - 4 } & Textile & 3165 & 40 \\
\cline { 2 - 4 } & Garment & 3515 & 40 \\
\cline { 2 - 4 } & Support & 1312 & 44 \\
\hline Worker health status & Diagnosed & 5276 & 16 \\
\cline { 2 - 4 } & Not diagnosed & 2716 & 66 \\
\cline { 2 - 4 } & & 34 \\
\hline
\end{tabular}

\section{Prevalence of registered diseases}


A total of 27320 consultations happen for different diagnoses for 5276 diagnosed workers that make an average of five consultations per worker during the study period. From the total number of consultations, the highest proportion was due to respiratory diseases (17\%). Further, the highest prevalence of diseases diagnosed at least one time per individual workers are identified as respiratory diseases (34\%) followed by MSD (29\%), gastrointestinal infection (21\%), peptic ulcer disease (19\%) and injury (17\%)(Table 2).

From the total number of consultations, the highest proportion was due to respiratory diseases $(17 \%)$. Further, the highest prevalence of diseases diagnosed at least one time per individual workers are identified as respiratory diseases (34\%) followed by MSD (29\%), gastrointestinal infection (21\%), peptic ulcer disease (19\%) and injury (17\%) (Table 2).

A total of 16993 workdays were lost due to health problems in the study period. Injury was the highest cause of sick leave days 2951 (17\%) followed by respiratory diseases $2327(14 \%)$. The number of workdays lost by departments was high 9027 (53\%) among textile department workers followed by garment workers 6415 (38\%) and support workers 1481 (9\%).In line with this, the highest proportion of workdays lost per number of workers was observed in the textile department; 2.8, 1.8 and 1.4 in the textile, garment and support, respectively. 
Table 2

Prevalence of diseases, frequency of consultations and sickness absence among all workers $(n=7992)$ in 2016-2017

\begin{tabular}{|c|c|c|c|c|c|}
\hline \multirow[t]{3}{*}{ Disease group } & \multirow{2}{*}{\multicolumn{2}{|c|}{$\begin{array}{l}\text { Prevalence of disease among the } \\
\text { workers ( } n_{1}=7992 \text { workers) }\end{array}$}} & \multirow{2}{*}{\multicolumn{2}{|c|}{$\begin{array}{l}\text { Number of } \\
\text { consultations per } \\
\text { disease } \\
\left(\mathrm{n}_{2}=27320\right. \\
\text { consultations) }\end{array}$}} & \multirow[t]{3}{*}{$\begin{array}{l}\text { Sick leave }{ }^{c} \\
\text { (workdays) }\end{array}$} \\
\hline & & & & & \\
\hline & Cases $^{a}$ & $\%$ & $\begin{array}{l}\text { Consultation } \\
\text { count }^{b}\end{array}$ & $\%$ & \\
\hline $\begin{array}{l}\text { Respiratory } \\
\text { diseases }\end{array}$ & 2711 & 34 & 4691 & 17.2 & 2327 \\
\hline $\begin{array}{l}\text { Musculoskeletal } \\
\text { diseases }\end{array}$ & 2312 & 29 & 3916 & 14.3 & 1949 \\
\hline $\begin{array}{l}\text { Gastrointestinal } \\
\text { infection }\end{array}$ & 1666 & 21 & 2294 & 8.4 & 931 \\
\hline Peptic ulcer & 1529 & 19 & 2306 & 8.4 & 1323 \\
\hline Injury & 1388 & 17 & 1918 & 7.0 & 2951 \\
\hline $\begin{array}{l}\text { Acute febrile } \\
\text { illness }\end{array}$ & 1325 & 17 & 2210 & 8.1 & 1822 \\
\hline $\begin{array}{l}\text { Neurological and } \\
\text { Psychiatric }\end{array}$ & 1335 & 17 & 1894 & 6.9 & 810 \\
\hline $\begin{array}{l}\text { Urinary tract } \\
\text { infection }\end{array}$ & 968 & 12 & 1358 & 5.0 & 527 \\
\hline Skin diseases & 876 & 11 & 1140 & 4.2 & 475 \\
\hline Mouth disease & 905 & 11 & 1129 & 4.1 & 397 \\
\hline Eye diseases & 833 & 10 & 1049 & 3.8 & 482 \\
\hline Allergy & 642 & 8 & 806 & 3.0 & 416 \\
\hline $\begin{array}{l}\text { Reproductive } \\
\text { health problem }\end{array}$ & 502 & 6 & 679 & 2.5 & 547 \\
\hline Ear problem & 251 & 3 & 298 & 1.1 & 92 \\
\hline Hemorrhoids & 132 & 2 & 172 & 0.6 & 77 \\
\hline Hypertension & 111 & 1 & 131 & 0.5 & 200 \\
\hline Anemia & 115 & 1 & 127 & 0.5 & 59 \\
\hline Diabetic & 67 & 1 & 105 & 0.4 & 99 \\
\hline Others & 798 & 10 & 1097 & 4.0 & 1509 \\
\hline
\end{tabular}


${ }^{a}$ number of workers diagnosed with the disease at least one time; ${ }^{b}=$ number of consultation by each disease; ${ }^{c}=$ number of workdays granted as sick leave for each disease, summarized for all the workers with this diagnosis

About $69 \%$ of the textile, $65 \%$ of the garment and $60 \%$ of the support workers have diagnosed at least for one disease condition during the study period. The proportion of textile department workers accounted $44 \%$ of the total work force; however, the overall proportion of disease diagnoses by the textile department workers is about $49 \%$.

In terms of disease type, a higher percent of respiratory, MSDs, injuries, peptic ulcer, AFI, mouth diseases, skin diseases, eye diseases, allergy, hemorrhoids and hypertension are identified among the textile department workers compared to the other two departments (Fig. 3). Gastrointestinal infections, neurology and psychiatric, urinary tract infection, reproductive illnesses and anemia are the highest reported by garment department workers. Respiratory disease is the most prevalent across the three working departments with $37 \%, 32 \%$ and $31 \%$ among textile, support and garment departments, respectively (Fig. 3). From the total workers who had at least one respiratory disease, 626 (23\%), 135(5\%), $84(3 \%)$ and 27 (1\%) were diagnosed to have bronchitis, asthma, pneumonia and tuberculosis, respectively. MSD was the second most prevalent group in all the three departments, $31 \%, 28 \%$ and $25 \%$ among textile, garment and support, respectively. Then, injury is the third most prevalent group among the textile department workers but it is number eighth among the garment department workers (Fig. 3).

\section{Factors associated with diagnostic category}

The statistical analysis uses the disease that is diagnosed at least one time for the individual workers as unit of analysis. Textile department workers have significantly higher odds for nine of the disease groups with adjusted odds ratio ranges (AOR: 1.35-2.07) compared to the support department workers, when adjusted for sex, education and age (Table 3 ). The garment department workers had significantly higher odds for four of the disease groups (AOR: 1.28-1.56) compared to the support department workers (Table 3). In these multiple logistic regression models female workers had significantly higher odds for seven of the disease groups (AOR: 1.24-14.7). Furthermore, workers with low educational status had significantly higher odds for six disease groups (AOR: 1.37-1.56) compared to workers of higher educational level (Table 3). Age of workers has significantly associated with 14 of the disease groups; an increased risk was observed with increased age (Table 3 ). 
Table 3

Multivariate analysis results of disease group among workers in the integrated textile factories $(n=7,992)$

Disease group

Respiratory

diseases

Musculoskeletal

disorders

Injuries

Gastrointestinal

infections
Bivariate analysis

Independent variables with a significance of $p<0.2$

Textile department

Female

Read and write

Age

Textile department

Garment department

Female

Read and write

Age

Textile department

Garment department

Female

Read and write

Age

Textile department

Garment department

Female
COR

$(95 \% \mathrm{Cl})$

1.24(1.08-

1.42)

0.91(0.82- $\quad 1.03(0.93-1.15)$

1.00)

$1.48(1.25-$

1.77)

1.12(0.93-1.35)

$1.03(1.02-$

1.03)

$1.03(1.02-1.03){ }^{*}$

$1.39(1.20-\quad 1.59(1.37-1.86)$ *

1.61)

$1.22(1.05-\quad 1.41(1.20-1.67)$ *

1.41)

1.11(1.01-

1.23)

$1.24(1.10-1.39)^{*}$

2.14(1.79-

2.54)

1.03(1.03-

1.04)

$1.86(1.56-$

2.22)

0.96(0.80-

1.15)

0.63(0.56-

$0.70)$

$0.72(0.63-0.82)$ *

1.62(1.32-

1.98)

$1.43(1.15-1.77)$ *

$1.01(1.01-$

1.02)

$1.01(1.00-1.02)$ *

$1.29(1.09-\quad 1.36(1.15-1.62)$ *

1.53)

$0.69(0.41-$

1.17)

$1.56(1.30-1.88)^{*}$

$0.59(0.42-\quad 1.07(0.94-1.21)$

$0.83)$ 


\begin{tabular}{|c|c|c|c|}
\hline & Read and write & $\begin{array}{l}1.25(1.03- \\
1.53)\end{array}$ & $1.13(0.92-1.40)$ \\
\hline & Age & $\begin{array}{l}1.03(1.01- \\
1.04)\end{array}$ & $1.01(1.01-1.02)$ * \\
\hline \multirow[t]{5}{*}{ Peptic ulcer } & Textile department & $\begin{array}{l}1.52(1.28- \\
1.81)\end{array}$ & $1.61(1.35-1.93)$ * \\
\hline & Garment department & $\begin{array}{l}1.33(1.12- \\
1.59)\end{array}$ & $1.26(1.04-1.53)$ * \\
\hline & Female & $\begin{array}{l}1.39(1.24- \\
1.56)\end{array}$ & $1.59(1.39-1.81)$ * \\
\hline & Read and write & $\begin{array}{l}1.66(1.37- \\
2.02)\end{array}$ & $1.31(1.06-1.61)$ * \\
\hline & Age & $\begin{array}{l}1.02(1.02- \\
1.03)\end{array}$ & $1.03(1.02-1.03)$ * \\
\hline \multirow[t]{5}{*}{ Acute febrile illness } & Textile department & $\begin{array}{l}1.38(1.17- \\
1.64)\end{array}$ & $1.46(1.23-1.74)$ * \\
\hline & Garment department & $\begin{array}{l}0.74(0.62- \\
0.89)\end{array}$ & $0.80(0.66-0.97)$ * \\
\hline & Female & $\begin{array}{l}0.81(0.72- \\
0.91)\end{array}$ & $1.05(0.91-1.20)$ \\
\hline & Read and write & $\begin{array}{l}1.76(1.44- \\
2.15)\end{array}$ & $1.49(1.20-1.84)$ * \\
\hline & Age & $\begin{array}{l}1.02(1.01- \\
1.02)\end{array}$ & $1.01(1.01-1.02)$ * \\
\hline \multirow[t]{5}{*}{ Allergies } & Textile department & $\begin{array}{l}1.25(1.00- \\
1.55)\end{array}$ & $1.56(1.24-1.96)$ * \\
\hline & Garment department & $\begin{array}{l}0.57(0.45- \\
0.73)\end{array}$ & $0.90(0.69-1.18)$ \\
\hline & Female & $\begin{array}{l}0.61(0.52- \\
0.72)\end{array}$ & $0.85(0.71-1.02)$ \\
\hline & Read and write & $\begin{array}{l}2.16(1.69- \\
2.77)\end{array}$ & $1.29(0.99-1.67)$ \\
\hline & Age & $\begin{array}{l}1.05(1.05- \\
1.06)\end{array}$ & $1.05(1.04-1.05)$ * \\
\hline \multirow[t]{3}{*}{ Mouth diseases } & Textile department & $\begin{array}{l}1.34(1.08- \\
1.66)\end{array}$ & $1.35(1.09-1.68)$ * \\
\hline & Garment department & $\begin{array}{l}1.23(1.00- \\
1.52)\end{array}$ & $1.10(0.87-1.39)$ \\
\hline & Female & $1.35(1.16-$ & $1.48(1.26-1.75)$ * \\
\hline
\end{tabular}


1.56)

Read and write

Age $1.22(0.95-\quad 1.07(0.82-1.40)$

1.58)

1.01(1.011.02)

$1.01(1.01-1.02)$ * 
Table 3

Continue

\begin{tabular}{|c|c|c|c|}
\hline \multirow[t]{2}{*}{ Disease groups } & \multicolumn{2}{|l|}{ Bivariate analysis } & \multirow{2}{*}{$\begin{array}{l}\begin{array}{l}\text { Multivariate } \\
\text { analysis }^{+}\end{array} \\
\text {AOR }(95 \% \mathrm{Cl})\end{array}$} \\
\hline & $\begin{array}{l}\text { Independent variables with a } \\
\text { significance of } p<0.2\end{array}$ & COR $(95 \% \mathrm{Cl})$ & \\
\hline \multirow[t]{2}{*}{ Anemia } & Garment department & $\begin{array}{l}1.97(1.09- \\
3.58)\end{array}$ & $1.16(0.61-2.18)$ \\
\hline & Female & $\begin{array}{l}3.23(1.99- \\
5.25)\end{array}$ & $2.95(1.74-5.02)$ \\
\hline \multirow[t]{4}{*}{ Hypertension } & Textile department & $\begin{array}{l}3.41(2.12- \\
5.48)\end{array}$ & $\begin{array}{l}1.94(1.17-3.23) \\
*\end{array}$ \\
\hline & Garment department & $\begin{array}{l}0.42(0.23- \\
0.76)\end{array}$ & $1.03(0.55-1.92)$ \\
\hline & Read and write & $\begin{array}{l}3.41(2.12- \\
5.48)\end{array}$ & $1.32(0.80-2.17)$ \\
\hline & Age & $\begin{array}{l}1.11(1.09- \\
1.13)\end{array}$ & $\begin{array}{l}1.10(1.08-1.13) \\
*\end{array}$ \\
\hline \multirow[t]{2}{*}{ Skin diseases } & Textile department & $\begin{array}{l}1.45(1.17- \\
1.80)\end{array}$ & $\begin{array}{l}1.48(1.19-1.83) \\
*\end{array}$ \\
\hline & Female & $\begin{array}{l}0.86(0.74- \\
0.99)\end{array}$ & $0.87(0.74-1.03)$ \\
\hline \multirow[t]{5}{*}{$\begin{array}{l}\text { Urinary tract } \\
\text { infections }\end{array}$} & Textile department & $\begin{array}{l}1.25(1.00- \\
1.55)\end{array}$ & $1.19(0.95-1.50)$ \\
\hline & Garment department & $\begin{array}{l}1.57(1.28- \\
1.94)\end{array}$ & $1.09(0.86-1.38)$ \\
\hline & Female & $\begin{array}{l}3.64(3.06- \\
4.33)\end{array}$ & $\begin{array}{l}4.77(3.94-5.79) \\
*\end{array}$ \\
\hline & Read and write & $\begin{array}{l}2.09(1.69- \\
2.60)\end{array}$ & $\begin{array}{l}1.45(1.14-1.84) \\
\text { * }\end{array}$ \\
\hline & Age & $\begin{array}{l}1.04(1.03- \\
1.04)\end{array}$ & $\begin{array}{l}1.05(1.04-1.06) \\
*\end{array}$ \\
\hline \multirow[t]{2}{*}{ Ear diseases } & Female & $\begin{array}{l}0.80(0.62- \\
1.03)\end{array}$ & $0.84(0.65-1.08)$ \\
\hline & Read and write & $\begin{array}{l}0.67(0.37- \\
1.20)\end{array}$ & $0.55(0.30-1.01)$ \\
\hline
\end{tabular}




\begin{tabular}{|c|c|c|c|}
\hline & Age & $\begin{array}{l}1.01(1.00- \\
1.03)\end{array}$ & $1.02(1.00-1.03)$ * \\
\hline \multirow[t]{4}{*}{ Eye diseases } & Garment department & $\begin{array}{l}0.74(0.60- \\
0.91)\end{array}$ & $0.91(0.72-1.15)$ \\
\hline & Female & $\begin{array}{l}0.69(0.60- \\
0.80)\end{array}$ & $0.78(0.66-0.92)$ \\
\hline & Read and write & $\begin{array}{l}1.29(0.99- \\
1.67)\end{array}$ & $1.11(0.85-1.46)$ \\
\hline & Age & $\begin{array}{l}1.01(1.01- \\
1.02)\end{array}$ & $1.01(1.00-1.02)$ * \\
\hline \multirow[t]{5}{*}{ Hemorrhoids } & Textile department & $\begin{array}{l}1.29(1.09- \\
1.53)\end{array}$ & $1.51(0.92-2.47)$ \\
\hline & Garment department & $\begin{array}{l}1.47(1.24- \\
1.73)\end{array}$ & $1.00(0.56-1.78)$ \\
\hline & Female & $\begin{array}{l}1.15(1.03- \\
1.29)\end{array}$ & $0.72(0.49-1.07)$ \\
\hline & Read and write & $\begin{array}{l}1.25(1.02- \\
1.53)\end{array}$ & ${ }_{*}^{1.02(1.01-1.04)}$ \\
\hline & Age & $\begin{array}{l}1.01(1.01- \\
1.02)\end{array}$ & $0.99(0.53-1.85)$ \\
\hline \multirow[t]{4}{*}{ Reproductive health } & Textile department & $\begin{array}{l}1.74(1.21- \\
2.49)\end{array}$ & $1.33(0.92-1.93)$ \\
\hline & Garment department & $\begin{array}{l}3.22(2.28- \\
4.54)\end{array}$ & $1.27(0.89-1.82)$ \\
\hline & Female & $\begin{array}{l}14.7(9.77- \\
22.30)\end{array}$ & $\begin{array}{l}14.64(9.58- \\
22.39)^{*}\end{array}$ \\
\hline & Age & $\begin{array}{l}0.99(0.98- \\
1.00)\end{array}$ & $1.01(1.00-1.02)$ * \\
\hline \multirow[t]{2}{*}{$\begin{array}{l}\text { Neurologic and } \\
\text { psychiatric }\end{array}$} & Garment department & $\begin{array}{l}1.37(0.94- \\
2.00)\end{array}$ & $1.04(0.69-1.58)$ \\
\hline & Female & $\begin{array}{l}1.73(1.30- \\
2.29)\end{array}$ & $\begin{array}{l}1.65(1.20-2.27) \\
*\end{array}$ \\
\hline \multirow[t]{2}{*}{ Diabetics } & Garment department & $\begin{array}{l}0.46(0.24- \\
0.87)\end{array}$ & $0.81(0.39-1.69)$ \\
\hline & Female & $\begin{array}{l}0.61(0.38- \\
0.99)\end{array}$ & $0.87(0.51-1.51)$ \\
\hline
\end{tabular}

$\mathrm{COR}=$ Crude odds ratio; $\mathrm{AOR}=$ Adjusted odds ratio; $\mathrm{Cl}=$ Confidence interval; ${ }^{+}$Multivariate analysis (all significant factors from bivariate analyses included) and * Significance level $\mathrm{P}<0.05$ 

significant factors from bivariate analyses included) and * Significance level $\mathrm{P}<0.05$

\section{Discussion}

This study shows that workers in the integrated textile factories were diagnosed with a wide range of diseases in one year period. Respiratory disease was the leading cause of morbidity followed by MSDs, whereas injuries caused more days away from work. Work in the textile departments, being female, older age and low educational status is associated with higher risk for most disease groups.

\section{The size of the problem}

Majority of workers $5276(66 \%)$ had developed at least one disease in the study period; but, some workers had more diseases, which made the total number of consultations 27320 . These figures are higher than reports from similar studies in other countries. For instance, a cross sectional study that evaluate the health conditions using clinical examinations of 514 male Indian textile workers found 754 disease conditions, which makes it 1.5 per worker (14). Again, a retrospective study from medical records of 1,906 workers from mobile clinics in Bangladesh textile and garment reported that $25 \%$ of the workers diagnosed with at least one disease conditions (15). A short survey that examined the occupational health conditions of 845 Indian textile workers found that 447 suffer from different disease (16).

Moreover, in the present study, the proportion of total diagnosed cases from the number of all workers in the factories is 3.4, which is higher than the proportion of total number of cases diagnosed from the general population 0.50 in Ethiopia (25). The total number of cases diagnosed in the general population excluding children less than five years age was 48.8 million given that the general populations count of Ethiopia 98.6 million (25). According to the Ministry of Health annual morbidity statistics report, the annual rate of outpatient visit for new and repeated health condition is 0.9 which is about four times less than our study population (25). This may indicate that workers from the integrated textile factories were diagnosed more diseases than the general population; however, the high percentage might also be associated with the better access to health services in the factories.

\section{Work-related factors}

The textile department workers had higher prevalence than the other workers for many diseases; for instance, respiratory diseases. Several other studies have also showed high prevalence of respiratory problems among the textile department workers $(7,16)$. An exposure assessment study by $(19)$ has measured higher dust exposure level among the textile production workers and the garment department 
workers in Ethiopia than the recommended threshold limit value in the ACGIH (26). This association might be due to the relationship between some respiratory diagnoses and high dust levels in the integrated factories, but the present study cannot answer this question due to the mixture of diagnoses in the categories used and lack of exposure measurements done in these particular factories. However, this study shows that a large percentage of the respiratory diseases are described as bronchitis and asthma; these diagnoses might link with the dust exposure.

MSD diagnoses are the second prevalent disease group in the present study and are significantly associated with work department. Both textile and garment department workers have higher odds of MSDs compared to the support department workers. Other studies have showed the presence of ergonomic hazards both in the textile and garment department that could increase the risk of MSDs (2729). Also, ergonomic hazard exposure assessment studies in Bangladesh and Cambodia found that the tasks in garment production gave high risk of $\operatorname{MSDs}(10,12)$. It is likely that the development of MSDs may be linked to exposure to ergonomic hazards in the textile and garment departments.

Further, injuries are also one of the most reported health problems and the major cause of sickness absence in this study. Both the textile and garment department workers work more with dangerous machines and have higher risk of injuries compared to workers in the support department. This implies that some of the injuries might be related to the working conditions in the textile and garment departments. However, the prevalence of injuries in this study is lower than in a study of self-reported injuries in another Ethiopian textile factory (20). The difference may associate with several factors; one the potential reason could be minor injuries that are managed by first aid may not include in the diagnostic reports of the factories health services.

Moreover, literatures indicate that textile factories have high noise levels in their production departments $(9,18)$; hence, one can expect that workers in this department with high prevalence of ear problem, as the noise may cause reduced hearing. However, our study did not show any difference among the textile and support workers regarding ear illnesses. This might be due to a failure to detect the reduced hearing among workers in this study; also, health offices did not have equipment to measure hearing ability in the targeted factories. Those workers who develop hearing problem may move from the textile department to

the support department to reduce their noise exposure as a medical intervention or may leave the job. The possibility of workers movement was indicated in a chronic respiratory assessment studies among textile workers $(6,30,31)$. Future studies should consider exposure intensity and interruption by tracing the detail of workers exposure profile.

\section{Personal factors}

Sex is significantly associated with most of the diseases registered in this study; female workers were diagnosed with more diseases compared to the males. A qualitative in-depth interviewing and focus group discussion with 24 female workers from Bangladesh indicated that female workers suffered from several types of diseases in the garment factories (32). The morbidity assessment study by Singh and 
colleagues (16) also revealed that female workers in the textile had more severe anemia than the males which is similar to the finding of the present study, and this might be related to the monthly menstrual cycle among females. Furthermore, a study in Bangladesh has reported higher prevalence of different diseases among the female workers than male workers, but found a lower prevalence of injuries among the females (15). Similarly, the current study shows lower prevalence of injuries among females; this might be due to their difference in task roles where men often work with machines while many machines in the textile industry expose workers to a high risk for injuries (20). An increased morbidity due to MSDs and respiratory diseases was also reported among female textile workers in India $(33,34)$. Similarly, a result from the current study found that females are with higher risk of MSDs than male but there is no difference in respiratory diseases.

In general, previous studies indicated that the high disease prevalence among the female textile and garment workers could be linked to the poor living conditions and those females are engaged in unhygienic work environment $(15,16,35-37)$. These factors need further study to explore the contexts of this working population.

This study shows that low educational status of workers in the textile and garment factories is associated with several disease groups, including injuries, MSD, peptic ulcer, UTI, AFI and hemorrhoids. Several studies have also revealed that workers in the textile and garment production with low educational status had an increased risk of developing different diseases $(16,36,38,39)$. Again, a study indicates the overall high morbidity of textile and garment workers in India which was significantly associated with low educational status (16). Also, a systematic review indicated that lower educational status could increase the health vulnerabilities of workers (13). This is supported by the result of a large study from WHO $(n=30,146)$ that shows low educational status of adults that significantly associated with MSD in the LMICs (40). The increased risk of diseases associated with low educational status could be due to the reason that most workers with low education are engaged in blue-collar jobs and they may not be aware of the presence of different workplace hazards and may have poor access to safety information at work.

Further again, worker's age is associated with the occurrence of diseases in this study; workers with an increased age have significantly higher risk for several diseases including respiratory, MSD, injury, ear diseases and gastrointestinal diseases than younger workers. Similarly, a study of general health problems assessment among female garment workers in India showed that older age workers have significantly higher risk for various diseases such as for respiratory diseases, gastrointestinal diseases, MSD and eye diseases compared to the young workers (17). This may due to the reason that older workers exposed to workplace hazards for many years that can increase their risk to develop diseases from cumulative exposures. Moreover, workers with work services greater than five years had significantly higher risk for 13 disease groups in the textile department compared to workers with service less than five years. 


\section{Different diagnoses than in the general population}

In this study, the most prevalent and top causes of morbidity is respiratory health (34\%) followed by MSD (29\%), GI (21\%), peptic ulcer (19\%) and injuries (17\%). The magnitude and type of morbidities are higher and different from the general population in Ethiopia. The prevalence of top leading diseases in the general population of Ethiopia are pneumonia (2.6\%), acute upper respiratory infection (2.4\%), typhoid (1.7\%), dyspepsia (1.6\%) and functional intestinal disorder (1.4\%) (25). Unlike the general population, most of the diseases from the textile and garment department in this study are non-communicable diseases that could be related to exposure to dust, ergonomic hazards, contact with chemicals and dangerous machines. Generally, workers in the integrated factories are different from the general population in many ways; they get a regular salary and can buy food and pay for housing; they have good access to health service and information; and the average age of workers is 40 years whereas the average age in the population is 20 year. Also, workers in the factories are likely to be selected segment of the population.

According to the ILO report (23), some of the diseases diagnosed among the textile and garment workers in the integrated factories could be work-related. The diseases are higher in magnitude and different from the diseases found in the general population; especially respiratory diseases, MSD, injury and ear diseases. The occurrence of these diseases might be due to the presence of hazards that are known to cause these health problems.

One of the strengths of this study is the inclusion of large number of workers that covers all workers in the factories from the three work departments of textile, garment and support. However, we do not know how representative the disease figures are when it comes to the real prevalence, since the workers may also visit other health institutions. On the other hand the factory clinics serve workers free of charge and have referral to hospitals for advanced diagnosis and treatment; hence, it is very likely that workers can consult the factory clinics to a large extent.

On the other hand, the weakness of this study is lack of standard diagnostic codes in the archives from the health clinics that enforces us to use large categories for the diagnoses. Also, we have limited information about the workers exposure profile and unable to collect the potential confounder variables such as previous health condition, current work exposure at the different departments, life style and behavioral related information. Hence, it is difficult to know the causes of different health problems. Using a control group from another factory might have improved the study. However, comparing groups inside the factory has advantages to link the heath problem by work conditions as the workers in the three departments had the same organizational experiences and the same factory culture.

\section{Conclusion}

About two-thirds of the workers in the integrated textile factories developed different types of diseases. The textile and garment department workers had higher risk to acquire these diseases compared to the 
support department workers, indicating that some of the diseases are related to work in these departments. Work department, gender, age and educational status of workers were significantly associated with most of the registered work-related diseases. Besides, the occurrence of respiratory, MSD, injuries and ear diseases were higher in magnitude than the general population. Factory clinics seem to be an important source of evidence to understand the occupational disease burden. Further study need to investigate the reason for repeated clinic consultation of some workers and the occurrence of rare chronic diseases such as cancer, heart diseases, renal diseases and diabetics in relation with workers exposure profile.

\section{Abbreviations}

ACIGH: American Conference of Government Industrial Hygienists

AFI: Acute febrile illness

AORs: Adjusted odds ratios

Cls: Confidence intervals

ILO: International Labor Organization

ITF: Integrated textile factory

LMICs: Low and middle income countries

MSDs: Musculoskeletal disorders

NORHED: Norwegian Program for Capacity Building in Higher Education and Research for Development

OHS: Occupational health service

COR: Crude odds ratio

SPSS: Statistical Package for Social Sciences

USA: United States of America

UTI: Urinary tract infection

WHO: World Health Organization

\section{Declarations}

- Ethics approval and consent to participate: Ethical approval was obtained from the Institutional Review Board of the College of Health Sciences at Addis Ababa University (Protocol number: 
057/16/SPH). An official letter from Addis Ababa University School of Public Health was sent to each factory to request for their participation in the study. The research team visited each factory and discussed with the factory managements about the purpose of the study and their voluntary participation. Access to the factory's human resource and clinic data was granted by the factory's management, as the archive was the property of the factory. We generated a unique identification number for each worker without the name of worker in the database during analysis and reporting to protect privacy.

- Consent for publication: Not Applicable

- Availability of data and materials: The datasets generated and analyzed during the current study are not publicly available due the information may affect the business firms but are available from the corresponding author on reasonable request.

- Competing interests: The authors declare that they have no competing interest.

- Funding: This research was funded by the Norwegian Program for Capacity Building in Higher Education and Research for Development (NORHED). The funded agency did not take part in thesis design, data collection and manuscript preparation process

- Authors' contributions: Y.T.Z. planned the study, collected and analyzed data, and drafted the manuscript in consultation with other authors. B.E.M., M.B., A.K., and W.D. participated in the design and the collection and analysis of data and provided scientific support throughout the project and commented on the manuscript. All authors have read and approved the final manuscript.

- Acknowledgements: We would like to thank the factories management and the health clinics staff.

\section{References}

1. Kim J-O, Traore M, Warfield C. The textile and apparel industry in developing countries. Text Prog. 2006; doi.org/10.1533/tepr.2006.0003

2. International Trade Center. Textile and Clothing Value Chain Road Map of Ethiopia (2016-2020). 2016; https://www.intracen.org/.../Ethiopia\%20TC\%20VCR\%205-2_web.pdf

3. Whewell CS, Abrahart EN.Textile. Encyclopædia Britannica: (2020); https://www.britannica.com/topic/textile

4. Schilling RSF. Byssinosis in the British cotton textile industry. Br Med Bull. 1950; 7(1-2):52-6.

5. Paudyal P, Semple S, Niven R, Tavernier G, Ayres JG. Exposure to Dust and Endotoxin in Textile Processing Workers. ANN OCCUP HYG. 2011;55(4):403-9.

6. Tefera Zele Y, Kumie A, Deressa W, Moen BE, Bråtveit M. Reduced Cross-Shift Lung Function and Respiratory Symptoms among Integrated Textile Factory Workers in Ethiopia. International journal of environmental research and public health. 2020;17(8):2741.

7. Khan $\mathrm{A} M \mathrm{MH}$, Kundi $\mathrm{M}$. Industrial hygiene, occupational safety and respiratory symptoms in the Pakistani cotton industry. BMJ Open. 2015;5: http://dx.doi.org/10.1136/bmjopen-2014-007266. 2015. 
8. Ivester AL, John D. Neefus. ILO Encyclopaedia of Occupational Health and Safety $4^{\text {th }}$ edition. Part XIV. Textile and Apparel Industries. Textile Goods Industry. https://wwwiloencyclopaediaorg/part-xiv42166/textile-goods-industry/item/877-the-textile-industry-history-and-health-and-safety. 2011.

9. Zaw AK, Myat AM, Thandar M, Htun YM, Aung TH, Tun KM, et al. Assessment of Noise Exposure and Hearing Loss among Workers in Textile Mill (Thamine), Myanmar: A Cross-sectional Study. Saf Health Work. 2020; 11(2):199-206

10. Hossain MD, Afzal A, Mahmudul Hassan Al I, Mahmud I, Imran Ahmed C, Razin Iqbal K, et al. Prevalence of work related musculoskeletal disorders (WMSDs) and ergonomic risk assessment among readymade garment workers of Bangladesh: A cross sectional study. PLoS One. 2018;13(7).

11. Aderaw Z, Engdaw D, Tadesse T. Determinants of Occupational Injury: A Case Control Study among Textile Factory Workers in Amhara Regional State, Ethiopia. J Trop Med. 2011;65:7275

12. Van L, Chaiear N, Sumananont C, Kannarath C. Prevalence of musculoskeletal symptoms among garment workers in Kandal province, Cambodia. J. Occup. Health. 2016; 58(1):107-17.

13. Kabir H, Maple M, Kim Usher Shahidul I. Health vulnerabilities of readymade garment (RMG) workers: a systematic review. BMC Public Health. 2019;19.

14. Tiwari R, Pathak M, Zodpey S, Babar V. Morbidity Profile of Cotton Textile Workers. Indian J Community Med. 2001;26(1):26

15. Solinap G, Wawrzynski J, Chowdhury N, Zaman H, Abid T, Hoque TA, et al. A disease burden analysis of garment factory workers in Bangladesh: proposal for annual health screening. International Health. 2018;11(1):42-51.

16. Singh MB, Fotedar R, Lakshminarayana J. Occupational morbidities and their association with nutrition and environmental factors among textile Workers of Desert Areas of Rajasthan, India. J Occup Health. 2005;47.

17. Ravichandran P, Shah S, Pankaj B. Health problems and risk factors prevailing among garment workers in Tirupur, Tamil Nadu. Int J Community Med Public Health. 2018. 2018;5(6):6.

18. Nada E, Ebraheem W, Sheta S. Noise-induced hearing loss among workers in textile factory. The Egyptian Journal of Otolaryngology. 2014;30(3):243-8.

19. Tefera Y, Schlünssen V, Kumie A, Deressa W, Moen B, Bråtveit M. Personal inhalable dust and endotoxin exposure among workers in an integrated textile factory. Arch Environ Occup Health. 2020; https://doi.org/10.1080/19338244.2020.1743958

20. Gebremichael G. The Prevalence and Associated Factors of Occupational Injury among Workers in Arba Minch Textile Factory, Southern Ethiopia: A Cross Sectional Study. Occup Med Health Aff. 2015;03.

21. Sudha B, Meenaxi T. Occupational health hazards in textiles industry. Asian J Home Sci. 2014;9.

22. Rantanen J, Fedotov IA. ILO Encyclopaedia of Occupational Health and Safety 4th edition. Part II. Health Care. Occupational Health Services. Standards, Principles and Approaches in Occupational 
Health Services. https://wwwiloencyclopaediaorg/part-iii-48230/topics-in-workers-compensationsystems/item/355-work-related-diseases-and-occupational-diseases-the-ilo-international-list. 2011

23. Lesage M. ILO Encyclopaedia of Occupational Health and Safety 4th edition. Part III. Workers's Compensation System. Work-Related Diseases and Occupational Diseases: The ILO International List. https://wwwiloencyclopaediaorg/part-iii-48230/topics-in-workers-compensationsystems/item/355-work-related-diseases-and-occupational-diseases-the-ilo-international-list. 2011.

24. Ethiopian Textile Industry Development Institute. TEXTILE INDUSTRY DEVELOPMENT IN ETHIOPIA: An Overview of Facts and Opportunities. https://www.germantech.org/Download/MEK_Ethiopia_Presentation_ETIDI_10.10.14.pdf. 2014.

25. Ministry of Health Ethiopia. Health and Health Related Indicators. Policy and Planning Directorate. Addis Ababa, Ethiopia. 2019. www.moh.gov.et

26. ACGIH. TLVs and BEls Based on the Documentation of the Threshold Limit Values for Chemical Substances and Physical Agents, and Biological Exposure Indices. American Conference of Governmental Industrial Hygienists Cincinnati; 2020: ACGIH.

27. Berberoğlu U, Tokuç B. Work-Related Musculoskeletal Disorders at Two Textile Factories in Edirne, Turkey. BALK MED J. 2013;30:23-7.

28. Paudyal P, Ayres JG, Semple S, Macfarlane GJ. Low back pain among textile workers: a crosssectional study. Occup. Med. 2013;63(2):129-34.

29. Abraha TH, Demoz AT, Moges HG, Ahmmed AN. Predictors of back disorder among Almeda textile factory workers, North Ethiopia. BMC Research Notes. 2018;11(1):304.

30. Lai PS, Christiani DC. Long term respiratory health effects in textile workers. Curr Opin Pulm Med. 2013;19(2):152-7.

31. Wang X, Zhang H-X, Sun B-X, Dai H-L, Hang J-Q, Eisen E, et al. Cross-shift airway responses and longterm decline in FEV1 in cotton textile workers. Am J Respir Crit Care Med. 2008;177(3):316-20.

32. Akhter S, Rutherford S, Chu C. Sewing shirts with injured fingers and tears: exploring the experience of female garment workers health problems in Bangladesh. BMC Int Health Hum Rights. 2019;19(1):2.

33. Thangaraj P, Kannappan S, Chacko T. Occupation-Related Health Status of Women Textile Workers in Tamil Nadu. Int. J. Preven. Curat. Comm. Med. 2019; 1(4).

34. Punita KP, Subita L, Roy G. Pattern of morbidity among female textile workers in Puducherry, South India. Int J Med Sci Public Health. 2016;6(3):140-143.

35. Makurat J, Friedrich H, Kuong K, Wieringa FT, Chamnan C, Krawinkel MB. Nutritional and Micronutrient Status of Female Workers in a Garment Factory in Cambodia. Nutrients. 2016;8(11):694.

36. Hasnain G, Akter M, Sharafat SI, Mahmuda A. Morbidity patterns, nutritional status, and healthcareseeking behavior of female garment workers in Bangladesh. Electron Physician. 2014;6(2):801-7. 
37. Huq AO, Mahmud HME, Haque KMF. Health Status, Occupational Hygiene \& Safety Practices among Female Workers in Bangladesh. Iran J Public Health. 2014;43(3):172-9.

38. Ahmad SA, Sayed M, Khan MH, Faruquee M, Yasmin N, Hossain Z, et al. Musculoskeletal Disorders and Ergonomic Factors among the Garment Workers. J Prev Soc Med. 2007;26(2):97-110.

39. Moges $\mathrm{H}$, Yessuf $\mathrm{S}$, Ahmed A. Magnitude and Characteristics of Occupational injury in Kombolcha textile factory, North East Ethiopia. Int J Occup Saf Ergon. 2013;3.

40. Stewart Williams J, Ng N, Peltzer K, Yawson A, Biritwum R, Maximova T, et al. Risk Factors and Disability Associated with Low Back Pain in Older Adults in Low- and Middle-Income Countries. Results from the WHO Study on Global AGEing and Adult Health (SAGE). PLOS ONE. 2015;10(6)

\section{Figures}

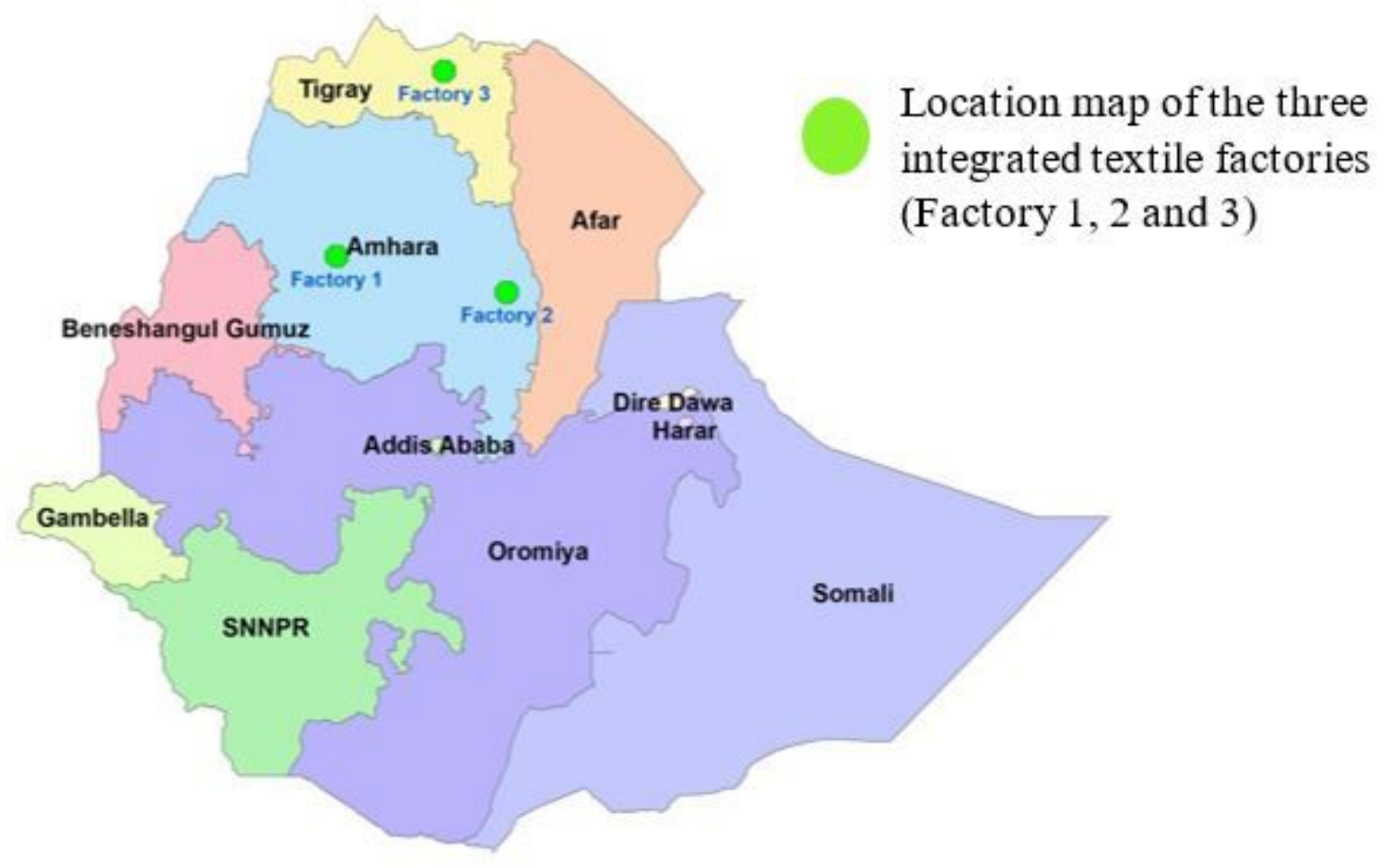

Source: http://commons. wikimedia.org/wiki

\section{Figure 1}

The three integrated textile factories location; two in Amhara and one in Tigray Regional State 


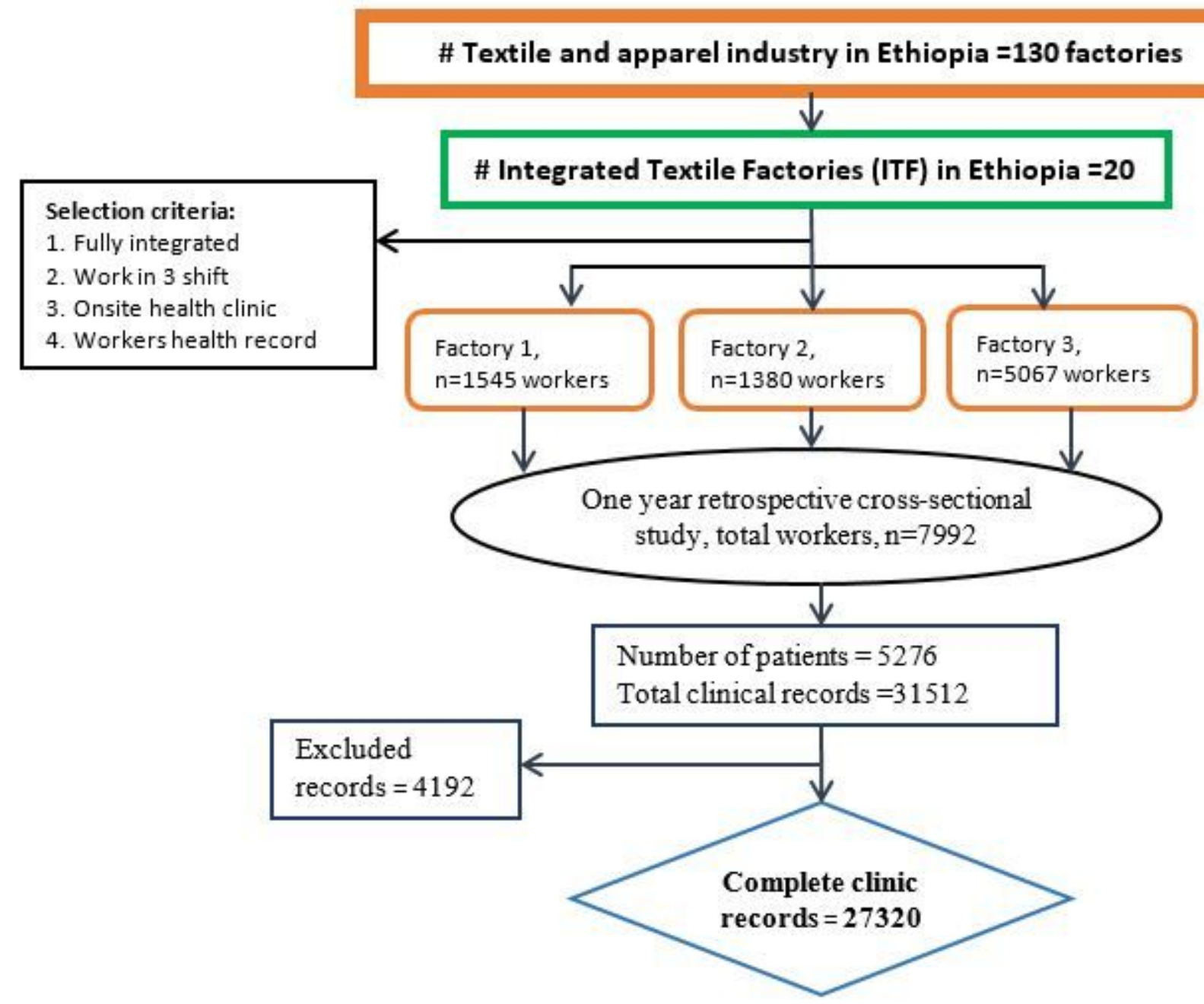

Figure 2

Illustrative diagram of the study population and data collection procedure of the integrated textile factories. 


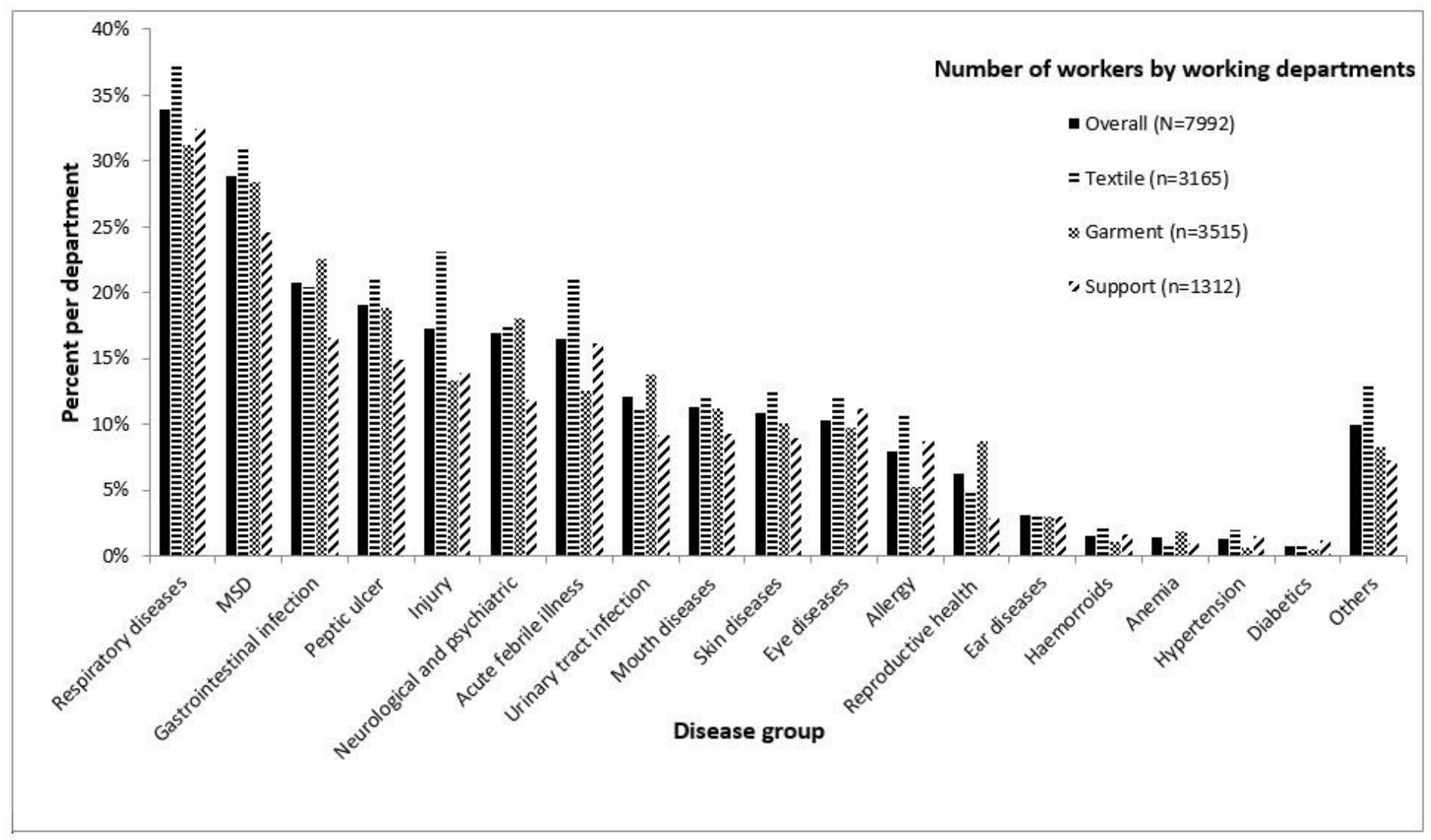

Figure 3

Prevalence of disease groups by working department in the integrated textile factories of Ethiopia, 20162017. 